Max-Planck-Institut für demografische Forschung

Max Planck Institute for Demographic Research

Konrad-Zuse-Strasse 1 - D-18057 Rostock - GERMANY

Tel +49 (0) 3812081 - 0; Fax +49 (0) 3812081 - 202;

http://www.demogr.mpg.de

MPIDR WORKING PAPER WP 2011-006

FEBRUARY 2011

\title{
Income inequality and population \\ health: a panel data analysis on 21 developed countries
}

Roberta Torre (torre.roberta@gmail.com)
Mikko Myrskylä (myrskyla@demogr.mpg.de)

(C) Copyright is held by the authors.

Working papers of the Max Planck Institute for Demographic Research receive only limited review. Views or opinions expressed in working papers are attributable to the authors and do not necessarily reflect those of the Institute. 


\title{
Income inequality and population health: a panel data analysis on 21 developed countries
}

\author{
Roberta Torre \\ torre.roberta@gmail.com
}

Mikko Myrskylä

myrskyla@demogr.mpg.de

Max Planck Institute for Demographic Research 


\begin{abstract}
The relative income-health hypothesis postulates that income distribution is one of the key determinants of population health. The discussion on the age and gender patterns of this association is still open. We test the relative income-health hypothesis using a panel data covering 21 developed countries for over 30 years. We find that net of trends in GDP per head and unobserved period and country factors, income inequality, measured by the Gini index, is strongly and positively associated with male and female mortality up to age 15 . For women the association vanishes at older ages, but for men persists up to age 50. These findings suggest that policies decreasing income inequality may improve the health of children and young- to middle-aged men. The mechanisms behind the income inequality-mortality association are not known, but may be related to parental stress and male competition. Future research could focus on unravelling these mechanisms.
\end{abstract}

Keywords: Income inequality; Population health; Mortality rates; Panel data; Developed countries 


\section{Introduction}

The income inequality-health hypothesis postulates that population health and mortality are importantly influenced by income distribution (Lynch et al. 2004). Evidence for the hypothesis would support redistributive policies aimed at decreasing income inequality. With some exceptions (Wagstaff and van Doorslaer 2000; Mellor and Milyo 2001; Gravelle et al. 2002; Beckfield 2004; Jen et al. 2009), most of recent research has been supportive of the hypothesis ( Shmueli 2004; De Vogli et al. 2005; Ram 2006; Dorling et al. 2007; Babones 2008; Karlsson et al. 2009; Biggs et al. 2010; Idrovo et al. 2010).

A large share of the research on income inequality and mortality has focused on the community and individual levels, as discussed in several review papers ( Wagstaff and van Doorslaer 2000; Macinko et al. 2003; Lynch et al. 2004; Wilkinson and Pickett 2006) . We study the income inequality-mortality link and focus on the population level association for three reasons. First, we are interested in understanding the population level health differences; second, income inequality by definition is a property of the population and not of the individual (Kaplan et al. 1996); and third, because the population level approach allows us to takes into account social and environmental reasons behind the association (Kawachi and Kennedy 1999; Wolfson et al. 1999; Wilkinson 1999; Wagstaff and van Doorslaer 2000; Wilkinson and Pickett 2009).

We analyze the income inequality-health hypothesis using a panel of 21 developed countries over the years 1975-2006 (see Appendix for a list of countries). The data allows us to control for all shared period factors and time-invariant country specific factors. We use mortality as the measure for health and the high-quality Human Mortality Database (2010) as the data source. The source for Gini index of income inequality, our income inequality measure, is the United Nations University-World Institue for Development Economics Research (UNU- 
WIDER) World Income Inequality Database (2010). In contrast to previous research that has looked at the population level association between income inequality and total mortality or life expectancy (Mellor and Milyo 2001; Beckfield 2004; De Vogli et al. 2005; Babones 2008), we distinguish between genders and age groups and control for trends in GDP per head and unobserved period and country factors.

Our results suggest that an increase in income inequality increases mortality at birth and up to age 15 for both genders. For women the association vanishes at ages above 15, but for men this association persists up to age 50. However, as the contribution of mortality at ages below 50 on life expectancy at birth is relatively small in developed countries, we find no effects of income inequality on life expectancy. Nevertheless, these findings highlight the importance of income inequality on the health and mortality of children and young- to middle-aged men, suggesting that redistributive policies decreasing income inequality could decrease mortality among these populations.

\section{Potential Mechanisms}

Mortality has continuously decreased over time, but since 1970s income inequality increased steadily in the industrialized nations (Subramanian and Kawachi 2004). As the average income per head explains only a small proportion of life expectancy among developed countries (Preston 1975), it has been suggested that income distribution might explain the differences in mortality across wealthy nations (Rodgers 1979). This "income inequalityhealth hypothesis" is based on the thought that within a population, an income inequality decreasing transfer from the rich to the poor would increase population level health as the marginal health gain is higher at lower income levels than the marginal health loss at higher 
income levels. Lynch, Smith, Kaplan \& House (2000) have classified the possible mechanisms through which income inequality and population health could be related as follows:

- the Individual Income Interpretation asserts that individual absolute income accounts for all the health effects of income distribution, and population health effects of income inequality are merely the sum of individual income effects (Gravelle 1998; Heerink, Mulatu and Bulte 2001; Gravelle et al. 2002);

- the Psychosocial Interpretation argues that individual health is affected by the perceptions that people have on their relative position in the social hierarchy, and lower positions may be related to lower investment in human capital, lack of social cohesion, and feelings of insecurity (Wilkinson 1992; Porta, Borrell and Copete 2002;).

- the Neo-material Interpretation suggests that income inequality affects health mainly through the lack of resources held by individuals and the systematic underinvestment in social and environmental conditions (Lynch et al., 2000).

\section{Prior Population Level Research}

Even though most of recent research finds an association between income inequality and health measures especially at the individual levels, the nature, magnitude and carachteristics on the population level association between income inequality and health are not well understood (Wagstaff and van Doorslaer 2000; Macinko et al. 2003; Lynch et al. 2004; Wilkinson and Pickett 2006). For example, in a review of 26 cross-country studies, 15 studies support the income inequality-health hypothesis, 5 showed mixed results and the remaining 6 
provided no evidence for the hypothesis (Lynch et al. 2004). The results were most consistent for infant mortality, but less so regarding adult mortality.

We believe that much of the heterogeneity in the findings depends often on the method used; data quality; and study populations. For example, some studies pool together less developed and developed countries (Rodgers 1979; Waldmann 1992; Karlsson et al. 2009) or perform only a cross-sectional analysis which fails to control for country-specific characteristics such as welfare systems (Judge et al. 1998; Pampel and Zimmer 1989; Wilkinson 1992; Lynch et al. 2001; De Vogli et al. 2005; Ram 2006; Idrovo et al. 2010). In addition, most studies especially at the individual level that support the income inequality-health hypothesis have been carried out after the mid 1990s. This can be interpreted as evidence for either the income inequality-health link changing over time, or better data quality and better methods providing less biased results (Judge 1995; Judge et al. 1998). Much of the early research that found an association between income inequality and health was based on cross-sectional analyses with no adjustment for potential confounders (e.g. welfare systems, environmental factors) (Rodgers 1979; Wilkinson 1992; McIsaac and Wilkinson 1997; Lynch et al. 2001).

In more recent papers, one cross-sectional analysis on 21 economically developed nations which controlled for income per head and educational achievements found the Gini index to be negatively associated with life expectancy at birth (De Vogli et al. 2005). A similar study using data on 126 countries found income inequality to be positively associated with mortality especially among men aged 15-29 (Dorling et al. 2007). Another cross-sectional study focusing on 75 countries, however, did not find any associations (Gravelle et al. 2002). Many of these cross-sectional studies suffer from one or more of these three shortcomings: use of simple bivariate methods without appropriate controls; no consideration for the possibility of unobserved country heterogeneity; or measures of income distribution that are often not internationally comparable (Beckfield 2004). There are only few population level comparative 
studies that use panel data and account for heterogeneity across countries (Mellor and Milyo 2001; Beckfield 2004; Babones 2008; Shkolnikov et al. 2009). Some of these studies, however, may be limited in statistical power as they use very short time series (e.g. 5 years) ( Mellor \& Milyo, 2001; Babones, 2008) or difficult to interpret because they pool together very different countries (Beckfield 2004; Babones 2008).

To our knowledge, the first study to make use of time series data analyzed 30 countries and implemented a first-differences model to control for country-specific effects (Mellor and Milyo 2001). The study does not find any evidence for the income inequality-health hypothesis, for a sample of twelve countries belonging to the Organization for Economic Cooperation and Development (OECD). However, the time series considered was quite short, only four years. Moreover, the use of a first-differences model may questionable. This is because if there is measurement error in the explanatory variable, as it might be the case for Gini time-series, first-differences model may exacerbate the asymptotic bias in the estimation of the coefficients. Beckfield (2004) analyzed 115 countries over 50 years and used a fixedeffect model to take into account unobserved heterogeneity, but found no evidence for the income inequality-health hypothesis. Babones (2008) analyzed 135 countries over a period from 1970 to 1995 and found that changes in income distribution are associated with changes in life expectancy and infant mortality. However, the association vanished when income per capita per head was added as control. A potential limitation of these studies is including such a heterogeneous sample of countries (i.e. pooling together transition economies with economically developed countries).

We also hypothesize that some of the inconsistencies in prior research may be due to mixing of sexes and different age groups (McIsaac \& Wilkinson 1997; Dorling et al. 2007; Kruger 2010). Mechanisms that explain the association might be different by gender and by age (e.g. children making invidious social comparisons as well as being affected by quality of family 
life, young adult men more keen on risk taking behaviors than women) (Courtenay, 2000; Pickett \& Wilkinson, 2007). In a recent paper, Shkolnikov et al. (2009) used data from 17 developed countries to analyze how income inequality is associated with life expectancy losses, a measure of the degree of variation in age at death within a country. Shkolnikov et al. (2009) used a country fixed-effect approach and a quinquennial time series for a set of comparable developed countries, and found that income inequality does not explain reduction in life expectancy losses over time, but it does explain differences in life expectancy losses across countries. In other words, income distribution may explain why some countries have higher inequality in life expectancy than in others. However, they do not distinguish among different age-intervals.

We build on prior research by extending the Shkolnikov et al. (2009) analysis from health inequality measures to absolute ones in order to test the income inequality-health hypothesis. We use a similar design to Shkolnikov et al. (2009) to analyze how mortality and life expectancy are associated with income inequality in developed nations. We perform a panel data analysis using random-effect models on 21 developed countries for a yearly time-series of more than 30 years and controlling for serial correlation. We pay particular attention to the methods (panel data), data quality (comparability, source reliability especially for income inequality) and appropriate selection of countries (economically developed nations), as these are suggested to be the main weaknesses in prior literature (Macinko et al. 2003). The selection of the countries analyzed is particularly important since there are significant differences in the effects of income inequality according to the type of countries considered (Moore 2006). We focus on developed countries with relatively stable past. Thus we exclude from the analysis former socialist countries as they have exhibited peculiar mortality trajectories since the collapse of the Soviet Union (Stuckler et al. 2009). 


\section{Data and methods}

Response variables: Life expectancy and mortality rates by age

We use data from the Human Mortality Database (HMD). The HMD provides internationally comparable data on mortality for national populations over long periods of time. In our time window, 1975-2006, we have only three years missing (2004-06) of observations for New Zealand only. Our focus is on developed countries as in wealthier nations the relation between population health and income per head may be weaker than for less developed countries (Preston 1975). We exclude countries that were part of the Soviet Bloc as mortality changes following the collapse of the Soviet Union might otherwise dominate the results.

We use life expectancy at birth and age-specific mortality rates as our response variables. Life expectancy at birth summarizes the mortality experience of a synthetic cohort over the life course, thus being a concise measure of population health. Life expectancy at birth also allows comparisons to existing research, as it has been used as the dependent variable in other comparable studies (Lynch et al. 2004). In order to gain understanding on how specific age groups respond to income inequality, we analyze age-specific mortality rates. We use age groups $0,1-14,15-49,50-64$, and $65-89$. These represent mortality experience in infancy, childhood, young adulthood, middle ages, and old ages.

Independent variables: The Gini coefficient and Gross Domestic Product (GDP) per head As the key independent variable, income inequality, we used the Gini index of income inequality. Data for the Gini coefficient are taken from UNU/WIDER World Income Inequality Database (last available version: May, 2008). The coefficient tells us how equally income is distributed across the population and is derived from the Lorenz curve that draws the proportion of the total income of the population earned by the bottom given percentage of 
the population. The Gini coefficient is then calculated as the ratio of the area that lies between the 45 degree line of perfect equality and the Lorenz curve over the total area under the line of perfect equality. It ranges between zero and one: the closer the coefficient is to one, the higher the degree of inequality is. The advantage of using Gini coefficient is that data are relatively easily available. In addition, the literature suggests that the association between income inequality and mortality is robust to the choice of the income inequality measure (Kawachi and Kennedy 1997).

We use data on Gini coefficient only for countries in which the income sharing unit is the household, the income concept refers to disposable income and the unit of analysis is the person. Of OECD countries for which data is available from the UNU/WIDER database, we drop Australia from the analysis as the data refers to person instead of household as the income sharing unit. We also drop Japan as the Gini data suggested surprising fluctuations and a decreasing trend over time, which is not consistent with published research (Jones 2007). After these exclusions we had time series data for 21 countries over the years 1975 2006.

Following Shkolnikov et al. (2009), we interpolated missing observations through a simple linear interpolation. As the Gini index evolves slowly over time, jumps and short-term fluctuations in the index are likely to be caused by measurement error rather than changes in the true income inequality. Therefore we applied a locally weighted (lowess) regression to smooth the time-series that otherwise would have shown irregular variations across time.

Our models control for income per head. As measure, data for Gross Domestic Product per head expressed in US\$ (constant prices and parity purchasing power, reference year 2000) 
have been collected from the OECD database. GDP per head data for Taiwan have been collected from the IMF web-site but are expressed in the same units as in the OECD database. Methods

The dataset constitutes a time-series of observations. Before regression we take logs of the variables to allow for an easier interpretation and comparison of the size of the estimated coefficients, and to control for heteroskedasticity and achieve linearity. We use panel data regression techniques to estimate the effect of income inequality on mortality. We control for country fixed-effects which control of unobserved factors that differ between countries but are constant over time for each country (e.g. welfare systems, geographical and environmental differences). We also control for time fixed-effects which control for unobserved factors that are shared by all countries at a specific point in time and are not accounted for by GDP per head. In addition, we adjust the model to account for autocorrelation. The following equation expresses the regression model:

$$
\ln Y_{i t}=\alpha+\beta_{1} \ln G D P_{i t}+\beta_{2} \ln \operatorname{Gini}_{i t}+\tau_{i}+\gamma_{t}+\varepsilon_{i t} \quad \text { with } \quad \varepsilon_{i t}=\rho \varepsilon_{i t-1}+\eta_{i t},
$$

where Y denotes the dependent variable (life expectancy at birth, or age-specific mortality rate) for country $i$ at time t; GDP is our control variable for income per head of country $i$ at time $t$; Gini is the index of income inequality for country $i$ at time $t$ and represents the main explanatory variable; $\tau_{\mathrm{i}}$ is the country heterogeneity term that is constant over time; $\gamma_{\mathrm{t}}$ is a period dummy capturing time fixed-effects (five year intervals starting from 1975 with the exception of 2000-2006, for which the interval is seven years long); and $\varepsilon_{\text {it }}$ is the error term which we allow to be serially correlated.

Controls for country fixed-effects may be implemented by differencing or by including fixedor random-effects in the model. Initially, we compared fixed-effect model versus a first- 
difference one. We preferred fixed-effect models to a first-difference model because of two reasons. First, differencing reduces the sample size and decreases statistical power. Second, if both the error term and the regressors are serially correlated, and the latter correlation is stronger, the first-difference estimator will worsen the asymptotic bias due to the measurement error (Wooldridge 2001).

As a following step, we compared the fixed-effect model to the random-effect model using the Hausman test. In most cases, the test preferred the specification with random effects for countries and fixed effects for periods. Given the relatively small number of observations, we preferred the random country and fixed period effect model over the alternative with both effects fixed (Wooldridge 2001). However, the results from these two models were qualitatively and quantitatively similar, leading to same conclusions.

Finally, we checked for serial correlation of the residuals using the Baltagi-Wu LBI test (Baltagi and $\mathrm{Wu} 1999$ ). Values for the test statistic were generally below 1.5, suggesting that there is serial correlation in the errors. Therefore we control for autocorrelation in the model. Our preferred model, then, is a panel model in which country heterogeneity is controlled for by using random-effects; time fixed-effects are controlled for by using five year period dummies; and autocorrelation in the residuals is allowed.

\section{Results}

\section{Descriptive results}

Table 1 shows descriptive statistics for all the variables. The table shows that there is large variation in both the Gini coefficient and GDP per head. For example, the difference between the largest and smallest Gini coefficients is more than $100 \%(46.5 \%$ for the United States in 
year 2004 vs. $20.3 \%$ for Sweden in year 1978). The mean Gini coefficient in the data is 29.8 , a figure consistent with prior research which has found the Gini coefficient to be on average $30 \%$ in OECD (Förster and Mira d'Ercole 2005).

Male life expectancy at birth is on average 73.1 years, ranging from 65.1 (for Portugal in 1975) to 79.5 years (for Iceland in 2003). As expected, female life expectancy at birth is on average six years higher than male, and has slightly less variation than male life expectancy. Mortality rates are higher among men than among women in all age groups, with the largest proportional difference in the age interval 15-49 years where male mortality is approximately two times female mortality.

\section{TABLE 1 ABOUT HERE}

Table 2 shows bivariate correlations across the main variables. The Gini coefficient is negatively correlated with life expectancy at birth (significant for men, not for women) and positively correlated with mortality rate for both men and women up to age 50. At ages 50-64, the correlation becomes insignificant and at ages 65-90 changes sign and is negatively correlated with mortality. Overall, the bivariate correlations suggest that a higher level of income inequality is linked to lower life expectancy at birth and higher mortality rates below age 50. For GDP per head, the results are similar for men and women, and suggest that higher average income is associated with increased life expectancy and decreased mortality in all age groups.

TABLE 2 ABOUT HERE 


\section{Regression results}

Table 3 reports the results of the regressions of life expectancy and age-specific mortality on the Gini coefficient. All models control for GDP per head, country random-effects, time fixed-effects, and allow for autocorrelation in the residuals. Figure 1 illustrates the key results shown in Table 3.

Table 3 presents the estimates for the twelve models implemented (six response variables, two genders). Each row shows the estimates according to the response variable considered and results are reported separately for men and for women. Columns refer to the explanatory variables introduced in the models. The first row shows the association between life expectancy at birth, Gini coefficient, and GDP per head. For both men and women, the Gini coefficient has a negative sign but is statistically not significant, suggesting that the importance of income inequality on life expectancy is small. GDP per capita, on the other hand, is strongly and positively associated with life expectancy. For example, the coefficient 0.055 for men suggests that a $1 \%$ increase in GDP per head leads to a $0.055 \%$ increase in life expectancy. With the average 73 years life expectancy for men, this corresponds to 15 days. While this number seems small, a doubling of GDP per head - which happens every 25 years with $3 \%$ growth rate - would increase life expectancy by almost three years. For women, the results are similar, so that a doubling of GDP per head corresponds to two years and a half increase in life expectancy. These calculations suggest that a large fraction of the overall increases in life expectancy over the last decades may be attributable to increasing wealth.

TABLE 3 ABOUT HERE

FIGURE 1 ABOUT HERE 
The following rows in Table 3 show results from regression models where age-specific mortality rates are regressed on the Gini index and GDP per head. For men, we observe positive and significant coefficients for Gini index up to age 50. Above this age, the coefficients are small, negative, and statistically insignificant. Among women, the coefficients are positive for all age intervals but significant at $p=0.05$ level only up to age 15 and with $p=0.10$ level up to age 50 . For higher ages the coefficients are statistically insignificant.

Thus, for both men and women, infant mortality is positively associated with income inequality. The magnitude and significance of the effects are also similar for men and women. The coefficient 0.47 for infant mortality (both men and women) suggests that a $1 \%$ increase in income inequality would increase infant mortality by $0.47 \%$. However, during our observation period, typical changes in the Gini coefficient are much larger. For instance, in the UK the Gini index increased by $43 \%$, from $23 \%$ to $33 \%$ in the period $1975-2006$. Such an increase in the Gini index corresponds to a nearly $20 \%$ increase in infant mortality for both men and women. This would imply that with baseline infant mortality rate 8/1000 (average infant mortality over our study period) and a population of 60 million people with 0.6 million infants (population size and age structure comparable to that of UK in 2009), the number of infant deaths per year would increase by almost 1,000 if income inequality increased by $43 \%$. In the actual data we observe today, this is not the case because other factors, such as increasing wealth, health, nutrition, medical care, and parental education, may offset this effect. Thus the effect of income inequality on infant mortality needs to be interpreted as a factor that may slow down the progress.

For mortality at ages 1-14, the coefficients are also positive and significant for both genders. For women, the magnitude of the coefficient is larger, but as child mortality is higher for men 
than for women, the absolute effect is slightly smaller than that of men. Again using U.K. as the example for an increase in the Gini index, a $43 \%$ increase in income inequality would correspond to $14 \%\left(1.43^{\wedge} 0.373\right)$ increase in child mortality for men and $16 \%\left(1.43^{\wedge} 0.424\right)$ increase for women. However, since mortality rate at ages 1-14 is lower for women than for men (in our data, on average $25 \%$ lower), the absolute effect is greater for men.

At ages $15-49$, the male mortality coefficient for Gini index is still positive (0.285) and highly significant $(\mathrm{p}<0.01)$. However, for women aged $15-49$ the coefficient size is $40 \%$ smaller than for men (0.171), and significant only at the $\mathrm{p}<0.10$ level. A $43 \%$ increase in the Gini index, which was observed in the U.K over the period 1975-2006, would correspond to a $11 \%$ increase in male mortality but only $6 \%$ increase in female mortality at ages $15-49$. This increases the mortality rates for men from $1.9 / 1000$ to $2.1 / 1000$ and for women from $0.9 / 1000$ to $1.0 / 1000$. With a U.K. population size and age structure, these mortality changes would correspond to approximately 3,100 excess male deaths but only 900 excess female deaths. Conversely, if the Gini coefficient declined from $30 \%$ (the average in our data) to $20 \%$ (the minimum in our data), then in a population with the size and structure of U.K and baseline mortality rates corresponding to the average in our sample, the number of lives saved between ages 14-49 would be similar: be 3,100 for men and 900 for women.

For the GDP per head predictor, we observe both among men and women a negative and significant association with all age-specific mortality rates. For both genders, the coefficients are of similar magnitude and decrease with age. For both men and women, the coefficient 0.30 at ages 1-14 suggests that a doubling of GDP per head would decrease child mortality by $30 \%$. For ages $65-90$, the corresponding decrease is $14 \%$ for both men and women. In 
absolute terms, however, the impact is much larger at older ages as mortality at ages $65-90$ is approximately 200 times higher than mortality at ages 1-14.

\section{Robustness checks}

We checked if the results were sensitive to exclusion of single countries. The results were robust against this check. We also checked if the inclusion of time fixed-effects would have influenced the results by re-estimating the models without time controls; the results changed only marginally. Finally, we estimated the models with income inequality lagged by one year. The results did not change in any significant manner.

\section{Discussion}

Rodgers (1979) and Wilkinson (1992) were among the first to provide evidence for the negative association between income inequality and population health. Part of recent research based on longitudinal data, however, has failed to find support for the income inequalityhealth hypothesis (Mellor and Milyo 2001; Beckfield 2004), and results from cross-sectional data have been mixed (Judge et al. 1998; Ellison 2002; Gravelle et al. 2002; Dorling et al. 2007). Recently, Shkolnikov et al. (2009) used longitudinal data to analyze the association between income inequality and life-expectancy losses, a measure of the variation in age at death within a country, and found that income inequality explains cross- but not withincountry differences in variation in age at death. We used a similar analytical design to Shkolnikov et al. (2009) to analyze how absolute measures of population health, namely life expectancy and age-specific mortality, depend on income inequality. We analyzed the association between income inequality and mortality by sex in 21 developed countries for the period 1975-2006 and found income inequality to be an important predictor of infant and 
child mortality for both sexes. In addition, income inequality predicted mortality at ages 1549 for men, but not for women.

These results shed new light on the income inequality-health hypothesis. A potential explanation as to why our results differ from some earlier studies (Judge 1995; Judge et al. 1998; Bobak et al. 2000; Mellor and Milyo 2001; Gravelle et al. 2002; Beckfield 2004) is that we focus only on developed countries (in contrast to Gravelle et al. 2002 and Beckfield 2004;); we exclude transition economies (in contrast to Bobak et al. 2000); and we use panel data models which allow controlling for unobserved country heterogeneity (in contrast to Gravelle et al. 2002; Judge 1995 and Judge et al. 1998). Finally, we consider separately genders and different age groups (in contrast to Mellor \& Milyo 2001 and Beckfield 2004).

We reach three main conclusions. First, results for life expectancy at birth do not reveal any association between income inequality and population mortality. For both male and female, regression coefficients are of the expected sign but very small and statistically not significant. This is a key aspect since we also show that an analysis of age-specific mortality rates reveals important income inequality-mortality links. Thus using life expectancy at birth as the single measure of population mortality hides important associations. Therefore, this constitutes an important limitation in some previous studies (Judge et al. 1998; Mellor and Milyo 2001; Gravelle et al. 2002; Beckfield 2004).

Second, when considering infant mortality and child mortality up to age 14, we find that increases in income inequality increases mortality for both genders. The life expectancy measures do not find this because life expectancy at birth includes all ages and therefore includes also age intervals when the association might be close to zero, slightly positive and 
insignificant. In addition, in developed world the influence of mortality at ages below 50 on life expectancy is limited.

Our finding on infant mortality is consistent with prior research (Wennemo 1993; Hales et al. 1999; Lynch et al. 2001). The mechanisms through which income inequality increases infant mortality, however, are not known. Infant mortality is strongly linked to poverty and social exclusion. Social underinvestment in services directed at mothers-to-be and their babies, as well as a lack of monetary support to families are likely candidates as mediators (Marmot 2003; Lundberg et al. 2008). It is possible that in societies with higher income inequality parents have to struggle more in order to maintain or improve their status in the social hierarchy. As a consequence, parents may invest, in relative terms, more energy in work in the attempt to avoid falling back in the social ladder, rather than investing in their children's wellbeing. Increasing income inequality may also increase stress levels. Stress, in turn, is related to pre-term births and short gestational length, both of which increase the probability of infant death (Huynh et al. 2005).

Our results show that the positive link between income inequality and mortality at ages 1-14 is similar for girls and for boys. This is consistent with recent individual level research (Collison, Dey, Hannah, \& Stevenson, 2007; Pickett, \& Wilkinson, 2007). As with infant mortality, at this stage of life the effect of income inequality on health is conveyed on the children through parents' resources and investment in offspring care. As discussed by Macinko et al. (2003), higher inequality may translate into higher levels of social stress; lower equality in access to resources; fewer investments in infrastructure and social security systems directed to the poorest; lower levels of social cohesion; and less trust and less mutual cooperation and higher opportunity costs for the parents. In particular, the opportunity cost of 
time in uneven societies is higher: parents have to struggle more to maintain or improve their position in the social ladder. Indeed, recent economic literature suggests that income inequality is associated with longer work hours and increase in household debt between (Bowles \& Park 2005; Iacoviello 2008). Parents may then be forced to spend more time working rather then raising the offspring. This may hinder the children's health and their probability of surviving, especially among those disabled or ill who require more resources and investment from the parents than an average child.

Third, we observe an important difference between genders in the association between income distribution and health when we focus on adults aged 15-49. For this age interval, we find a strong positive association between income inequality and mortality for men. For women, the association is weaker and only marginally significant. Backlund et al. (2007) found a similar gender difference for ages 25-64 in an analysis of 50 U.S. states: income inequality was associated more with male than female mortality. Dorling et al. (2007) also found a gender difference in favor of women using data for OECD countries. A plausible explanation for this gender difference comes from sexual selection theory that among young adults, men have higher incentive than women to compete and advance their position in the social hierarchy as higher status increases the success in finding a mate more for men than it does for women (Kruger 2010). Therefore higher income inequality cannot but foster a stronger competition and risk-taking behaviors. The male-male competition may also increase testosterone levels and increase the propensity to take potentially fatal risks (Ferrini and Barrett-Connor 1998; Wilson et al. 2002). Moreover, in societies where men are typically the bread-winners, men by definition carry higher responsibility for supporting the family financially. In an unequal society, men may be more exposed to the stress of maintaining or improving the family's socioeconomic status. A step forward from our analysis would be to look at how income 
inequality influences male excess mortality. An analysis by cause of death would also allow a better understanding on which pathways are at work in explaining this association.

Finally, for the ages above 50, we do not find any association between mortality and income inequality. It is possible that at later stages of adulthood as well as at old ages, most men have secured their position in the social hierarchy and most mating and reproduction have already taken place. Consequently, there is less incentive to adopt competitive and risk-taking behaviors that hinder men's health. This hypothesis would be consistent with the fact that male testosterone levels, which are correlated with risk-taking behavior, decrease with age (Ferrini and Barrett-Connor 1998). Alternative explanation could be selection, so that those who survived to age 50 either were never affected by the negative effects of the income inequality or represent the selected successful individuals.

In summary, our results show that in developed countries income inequality has an important effect on child and adult mortality, but not on old-age mortality. The importance of average income level, however, is higher than the importance of income distribution. Nevertheless, our results suggest that the recent skepticism (Gravelle et al. 2002; Lynch and Smith 2002) on the income inequality-health hypothesis needs to be reconsidered. While our population level analysis cannot disentangle the problem related to the concave association between income and individual health, our analysis shows that societies where income distribution is equal have lower infant, child and young adult mortality than societies where income distribution is unequal. Moreover, income distribution is associated more with young adult men than women mortality, introducing an interesting and relevant gender difference worth of further study. Given the importance of health on productivity as well as sustainability of an aging society, redistributive policies aimed at reducing income inequality might lead, in addition to improved population health, to general positive spillover effects in the society. 


\section{References}

Babones, S.J. 2008. "Income inequality and population health: Correlation and causality." Social Science \& Medicine 66(7): 1614-1626.

Backlund, E., G. Rowe, J. Lynch, M.C. Wolfson, G.A. Kaplan, and P.D. Sorlie. 2007. "Income inequality and mortality: a multilevel prospective study of 521248 individuals in 50 US states." Int. J. Epidemiol. 36(3): 590-596.

Baltagi, B.H.and P.X. Wu. 1999. "Unequally Spaced Panel Data Regressions with AR(1) Disturbances." Econometric Theory 15(6): 814-823.

Beckfield, J. 2004. "Does Income Inequality Harm Health? New Cross-National Evidence." Journal of Health and Social Behavior 45(3): 231-248.

Biggs, B., King, L., Basu, S., \& Stuckler, D. 2010. "Is wealthier always healthier? The impact of national income level, inequality, and poverty on public health in Latin America." Social Science \& Medicine 71(2): 266-73.

Bobak, M., H. Pikhart, R. Rose, C. Hertzman, and M. Marmot. 2000. "Socioeconomic factors, material inequalities, and perceived control in self-rated health: cross-sectional data from seven post-communist countries." Social Science \& Medicine 51(9): 1343-1350.

Bowles, S., \& Park, Y. 2005. "Emulation, Inequality, and Work Hours: Was Thorsten Veblen Right?" The Economic Journal 115(507): F397-412.

Collison, D., Dey, C., Hannah, G., \& Stevenson, L. 2007. "Income inequality and child mortality in wealthy nations." Journal of Public Health 29(2): 114-117.

Courtenay, W.H. 2000. "Constructions of masculinity and their influence on men's wellbeing: a theory of gender and health." Social Science \& Medicine 50(10): 1385-401. 
De Vogli, R., R. Mistry, R. Gnesotto, and G.A. Cornia. 2005. "Has the relation between income inequality and life expectancy disappeared? Evidence from Italy and top industrialized countries." J Epidemiology and Community Health 59(2): 158-162.

Dorling, D., R. Mitchell, and J. Pearce. 2007. "The global impact of income inequality on health by age: an observational study." BMJ 335(7625): 873-.

Ellison, G.T.H. 2002. "Letting the Gini out of the bottle? Challenges facing the relative income hypothesis." Social Science \& Medicine 54(4): 561-576.

Ferrini, R.L.and E. Barrett-Connor. 1998. "Sex Hormones and Age: A Cross-sectional Study of Testosterone and Estradiol and Their Bioavailable Fractions in Community-dwelling Men." Am. J. Epidemiol. 147(8): 750-754.

Förster, M.and M. Mira d'Ercole. 2005. "Income Distribution and Poverty in OECD Countries in the Second Half of the 1990s." OECD Social, Employment and Migration Working Papers(22)

Gravelle, H. 1998. "How much of the relation between population mortality and unequal distribution of income is a statistical artefact?" BMJ 316(7128): 382-385.

Gravelle, H., J. Wildman, and M. Sutton. 2002. "Income, income inequality and health: what can we learn from aggregate data?" Social Science \& Medicine 54(4): 577-589.

Hales, S., P. Howden-Chapman, C. Salmond, A. Woodward, and J. Mackenbach. 1999. "National infant mortality rates in relation to gross national product and distribution of income." The Lancet 354(9195): 2047-2047.

Heerink, N., A. Mulatu, and E. Bulte. 2001. "Income inequality and the environment: aggregation bias in environmental Kuznets curves." Ecological Economics 38(3): 359-367. 
Human Mortality Database. (2010). University of California, Berkeley (USA) and Max Planck Institute for Demographic Research (Germany). Available at http://www.mortality.org/ (Accessed in March 2010).

Huynh, M., J.D. Parker, S. Harper, E. Pamuk, and K.C. Schoendorf. 2005. "Contextual effect of income inequality on birth outcomes." Int. J. Epidemiol. 34(4): 888-895.

Iacoviello, M. (2008). "Household Debt and Income Inequality, 1963-2003." Journal of Money, Credit and Banking 40(5): 929-965.

Idrovo, A.J., Ruiz-Rodriguez, M., \& Manzano-Patino, A.P. 2010. "Beyond the income inequality hypothesis and human health: a worldwide exploration." Rev Saude Publica 44(4): 695-702.

Jen, M.H., Jones, K., \& Johnston, R. 2009. "Global variations in health: evaluating Wilkinson's income inequality hypothesis using the World Values Survey." Social Science \& Medicine 68(4): 643-53.

Jones, R.S. 2007. "Income Inequality, Poverty and Social Spending in Japan." OECD Economics Department Working Papers No. 556.

Judge, K. 1995. "Income distribution and life expectancy: a critical appraisal." BMJ 311(7015): 1282-1285.

Judge, K., J.-A. Mulligan, and M. Benzeval. 1998. "Income inequality and population health." Social Science \& Medicine 46(4-5): 567-579.

Kaplan, G., E. Pamuk, J. Lynch, and J. Balfour. 1996. "Inequality in income and mortality in the United States: analysis of mortality and potential pathways." BMJ 312(7037): 999-1003. 
Karlsson, M., Nilsson, T., Lyttkens, C.H., \& Leeson, G. 2009. "Income inequality and health: importance of a cross-country perspective." Social Science \& Medicine 70(6): 875-85.

Kawachi, I.and B.P. Kennedy. 1997. "The relationship of income inequality to mortality: Does the choice of indicator matter?" Social Science \& Medicine 45(7): 1121-1127.

Kawachi, I. and Kennedy, B. P. 1999. "Income inequality and health: pathways and mechanisms." Health Services research 34(1 Pt 2): 215-227.

Kruger, D.J. 2010. " Socio-demographic factors intensifying male mating competition exacerbate male mortality rates." Evolutionary Psychology 8(2): 194-204.

Lundberg, O., Yngwe, M.A., Stjärne, M.K., Elstad, J.I., Ferrarini, T., Kangas, O., Norström, T., Palme, J., Fritzell, J., NEWS Nordic Expert Group. 2008. "The role of welfare state principles and generosity in social policy programmes for public health: an international comparative study." Lancet 372(9650): 1633-40.

Lynch, J.and G.D. Smith. 2002. "Commentary: Income inequality and health: The end of the story?" Int. J. Epidemiol. 31(3): 549-551.

Lynch, J., G.D. Smith, S. Harper, M. Hillemeier, N. Ross, G.A. Kaplan, and M. Wolfson. 2004. "Is Income Inequality a Determinant of Population Health? Part 1. A Systematic Review." The Milbank Quarterly 82(1): 5-99.

Lynch, J., G.D. Smith, M. Hillemeier, M. Shaw, T. Raghunathan, and G. Kaplan. 2001. "Income inequality, the psychosocial environment, and health: comparisons of wealthy nations." The Lancet 358(9277): 194-200. 
Lynch, J., G.D. Smith, G.A. Kaplan, and J.S. House. 2000. "Income inequality and mortality: importance to health of individual income, psychosocial environment, or material conditions." BMJ 320(7243): 1200-1204.

Macinko, J.A., L. Shi, B. Starfield, and J.T. Wulu, Jr. 2003. "Income Inequality and Health: A Critical Review of the Literature." Med Care Res Rev 60(4): 407-452.

Marmot, M.G. 2003. "Understanding Social Inequalities in Health." Perspectives in Biology and Medicine 46(3): S9-S23.

McIsaac, S.J.and R.G. Wilkinson. 1997. "Income distribution and cause-specific mortality." Eur J Public Health 7(1): 45-53.

Mellor, J.M.and J. Milyo. 2001. "Reexamining the Evidence of an Ecological Association between Income Inequality and Health." Journal of Health Politics Policy and Law 26(3): $487-522$

Moore, S. 2006. "Peripherality, income inequality, and life expectancy: revisiting the income inequality hypothesis." Int. J. Epidemiol. 35(3): 623-632.

OECD.Stat. 2008. Organization for Economic Development and Cooperation. Available at http://stats.oecd.org/index.aspx?r=242437

Pampel, F.C.and C. Zimmer. 1989. "Female labour force activity and the sex differential in mortality: Comparisons across developed nations, 1950-1980." European Journal of Population/Revue européenne de Démographie 5(3): 281-304.

Pickett, K.E., \& Wilkinson, R.G. 2007. "Child wellbeing and income inequality in rich societies: ecological cross sectional study." BMJ 335(7629): 1080. 
Porta, M., C. Borrell, and J.L. Copete. 2002. "Commentary: Theory in the fabric of evidence on the health effects of inequalities in income distribution." Int. J. Epidemiol. 31(3): 543-546.

Preston, S.H. 1975. "The Changing Relation between Mortality and Level of Economic Development." Population Studies 29(2): 231-248.

Ram, R. 2006. "Further examination of the cross-country association between income inequality and population health." Social Science \& Medicine 62(3): 779-91.

Rodgers, G.B. 1979. "Income and Inequality as Determinants of Mortality: An International Cross-Section Analysis." Population Studies 33(2): 343-351.

Shkolnikov, V., E.M. Andreev, Z. Zhang, J. Oeppen, and J.W. Vaupel. 2009. "Losses of expected lifetime in the US and other developed countries: methods and empirical analyses." MPIDR Working Paper.

Shmueli, A. 2004. "Population health and income inequality: new evidence from Israeli timeseries analysis." Int. J. Epidemiol. 33(2): 311-317.

Stuckler, D., L. King, and M. McKee. 2009. "Mass privatisation and the post-communist mortality crisis: a cross-national analysis." The Lancet 373(9661): 399-407.

Subramanian, S.V. and I. Kawachi. 2004. "Income Inequality and Health: What Have We Learned So Far?" Epidemiol Rev 26(1): 78-91.

UNU-WIDER World Income Inequality Database, Version 2.0c. 2008. United Nations University-World Institute for Development Economics Research. Available at http://www.wider.unu.edu/research/Database/en_GB/database/ 
Wagstaff, A. and E. van Doorslaer. 2000. "Income inequality and health: What does the literature tell us?" Annual Review of Public Health 21: 543-567.

Waldmann, R.J. 1992. "Income Distribution and Infant Mortality." The Quarterly Journal of Economics 107(4): 1283-1302.

Wennemo, I. 1993. "Infant mortality, public policy and inequality: a comparison of 18 industrialised countries 1950-85." Sociology of Health \& Illness 15(4): 429-446.

Wilkinson, R.G. 1992. "Income Distribution And Life Expectancy." BMJ: British Medical Journal 304(6820): 165-168.

Wilkinson, R. G. 1999. "Two Pathways, but How Much Do They Diverge?" BMJ: British Medical Journal 319(7215): 956-957.

Wilkinson, R.G. and K.E. Pickett. 2006. "Income inequality and population health: A review and explanation of the evidence." Social Science \& Medicine 62(7): 1768-1784.

Wilkinson, R.G. and K.E. Pickett. 2009. "Income Inequality and Social Dysfunction." Annual Review of Sociology 35(1): 493-511.

Wilson, M., Daly, M., \& Pound, N. 2002. "An evolutionary psychological perspective on the modulation of competitive confrontation and risk taking." Hormones, Brain and Behavior 5: $381-408$.

Wolfson, M., G. Kaplan, J. Lynch, N. Ross, E. Backlund, H. Gravelle, and R.G. Wilkinson. 1999. "Relation between income inequality and mortality: empirical demonstration • Diminishing returns to aggregate level studies - Two pathways, but how much do they diverge?" BMJ 319(7215): 953-957. 
Wooldridge, J. 2001. Econometric Analysis of Cross Section and Panel Data: The MIT Press.

World Economic Outlook Database. 2008. International Monetary Fund. Available at https://www.imf.org/external/ns/cs.aspx?id=28 


\section{APPENDIX}

\section{List of sample countries}

Austria, Belgium, Canada, Denmark, United Kingdom, Finland, France, Germany, West

Germany, Iceland, Italy, Luxembourg, Netherlands, New Zealand, Norway, Portugal, Spain,

Sweden, Switzerland, Taiwan and United States. 


\section{TABLES AND FIGURES}

Table 1.

Descriptive statistics on the Gini Coefficient, GDP per head, life expectancy and age-specific mortality.

\begin{tabular}{lcccc}
\hline \multicolumn{1}{c}{$\mathbf{N = 5 5 1}$} & Mean & Std. dev. & Min. & Max. \\
\hline Gini coefficient (\%) & 29.79 & 5.11 & 20.32 & 46.54 \\
GDP per head & $\$ 19,048$ & $\$ 10,054$ & $\$ 3,071$ & $\$ 78,138$ \\
MALE & & & & \\
Life expectancy at birth & 73.10 & 2.60 & 65.14 & 79.49 \\
Mortality rates by age & & & & \\
0 & 8.81 & 4.81 & 1.34 & 45.27 \\
$1-14$ & 0.33 & 0.16 & 0.06 & 1.16 \\
15-49 & 1.92 & 0.50 & 0.73 & 3.41 \\
50-64 & 11.51 & 2.66 & 6.03 & 19.76 \\
65-90 & 63.05 & 7.75 & 45.93 & 84.89 \\
FEMALE & & & & \\
Life expectancy at birth & 79.35 & 2.18 & 73.55 & 84.13 \\
Mortality rates by age & & & & \\
0 & 6.96 & 3.68 & 1.00 & 35.95 \\
1-14 & 0.24 & 0.11 & 0.00 & 0.87 \\
15-49 & 0.92 & 0.21 & 0.49 & 1.62 \\
50-64 & 5.82 & 1.32 & 3.06 & 10.58 \\
65-90 & 45.71 & 6.28 & 30.40 & 64.32 \\
& & & & \\
\hline
\end{tabular}

Note: Data on GDP per head are from the OECD on-line database (with the only exception of Taiwan, for which data are from the IMF web-site) and are expressed in US\$, constant prices and PPP's (2000); data on Gini coefficients are from the WIID database, version 2008; data on mortality rates and life expectancy at birth are from the Human Mortality Database (2010). Mortality rates are here expressed in per thousand person-years. 


\section{Table 2.}

Bivariate correlations between the Gini coefficient, GDP per head, life expectancy and agespecific mortality

\begin{tabular}{|c|c|c|c|c|}
\hline $\mathrm{N}=551$ & & & & \\
\hline \multirow[b]{2}{*}{ Variables } & \multicolumn{2}{|l|}{ Male } & \multicolumn{2}{|l|}{ Females } \\
\hline & Gini & $\begin{array}{c}\text { GDP per } \\
\text { head }\end{array}$ & Gini & $\begin{array}{c}\text { GDP per } \\
\text { head }\end{array}$ \\
\hline Life expectancy at birth & $-0.09 * *$ & $0.75 * *$ & -0.06 & $0.71 * *$ \\
\hline \multicolumn{5}{|l|}{ Mortality rates by age } \\
\hline 0 & $0.29 * *$ & $-0.65 * *$ & $0.31 * *$ & $-0.64 * *$ \\
\hline $1-14$ & $0.24 * *$ & $-0.70 * *$ & $0.25^{* *}$ & $-0.69 * *$ \\
\hline $15-49$ & $0.28 * *$ & $-0.56 * *$ & $0.23 * *$ & $-0.59 * *$ \\
\hline $50-64$ & 0.02 & $-0.70 * *$ & 0.06 & $-0.55 * *$ \\
\hline $65-90$ & $-0.14 * *$ & $-0.71 * *$ & $-0.09 * *$ & $-0.70 * *$ \\
\hline
\end{tabular}


Table 3.

Regression results of life expectancy and age-specific mortality on Gini index and GDP per head.

\begin{tabular}{|c|c|c|c|c|c|c|}
\hline \multicolumn{7}{|l|}{$\mathrm{N}=551$} \\
\hline \multirow[b]{2}{*}{ Response Variable } & \multicolumn{3}{|l|}{ Male } & \multicolumn{3}{|l|}{ Females } \\
\hline & Gini & GDP per head & $R^{2}$ & Gini & GDP per head & $R^{2}$ \\
\hline Life expectancy at birth & -0.011 & $0.055 * *$ & 0.65 & -0.014 & $0.045 * *$ & 0.59 \\
\hline \multicolumn{7}{|l|}{ Mortality rates by age } \\
\hline Age 0 & $0.470 * *$ & $-0.648 * *$ & 0.70 & $0.465 * *$ & $-0.634 * *$ & 0.68 \\
\hline Ages 1-14 & $0.373 * *$ & $-0.512 * *$ & 0.75 & $0.424 * *$ & $-0.493 * *$ & 0.75 \\
\hline Ages $15-49$ & $0.285^{*}$ & $-0.295 * *$ & 0.40 & $0.171^{\dagger}$ & $-0.304 * *$ & 0.45 \\
\hline Ages 50-64 & -0.031 & $-0.308 * *$ & 0.57 & 0.038 & $-0.288 * *$ & 0.33 \\
\hline Ages $65-90$ & -0.025 & $-0.213 * *$ & 0.58 & 0.055 & $-0.220 * *$ & 0.54 \\
\hline
\end{tabular}

${ }^{\ddagger} \mathrm{p}<0.1 ;{ }^{*} \mathrm{p}<0.05 ; * * \mathrm{p}<0.01$. Standard errors in parenthesis

Note: Twelve models are estimated (six dependent variables, men and women separately) using a panel of 21 countries from 1975 to 2006. All variables are expressed in logarithmic scale. The models control for GDP per head, country random-effects and time fixed-effects (five year intervals starting from 1975 with the exception of 2000-2006, for which the interval is 7 years long) and allow for autocorrelation in the residuals. 
Figure 1.

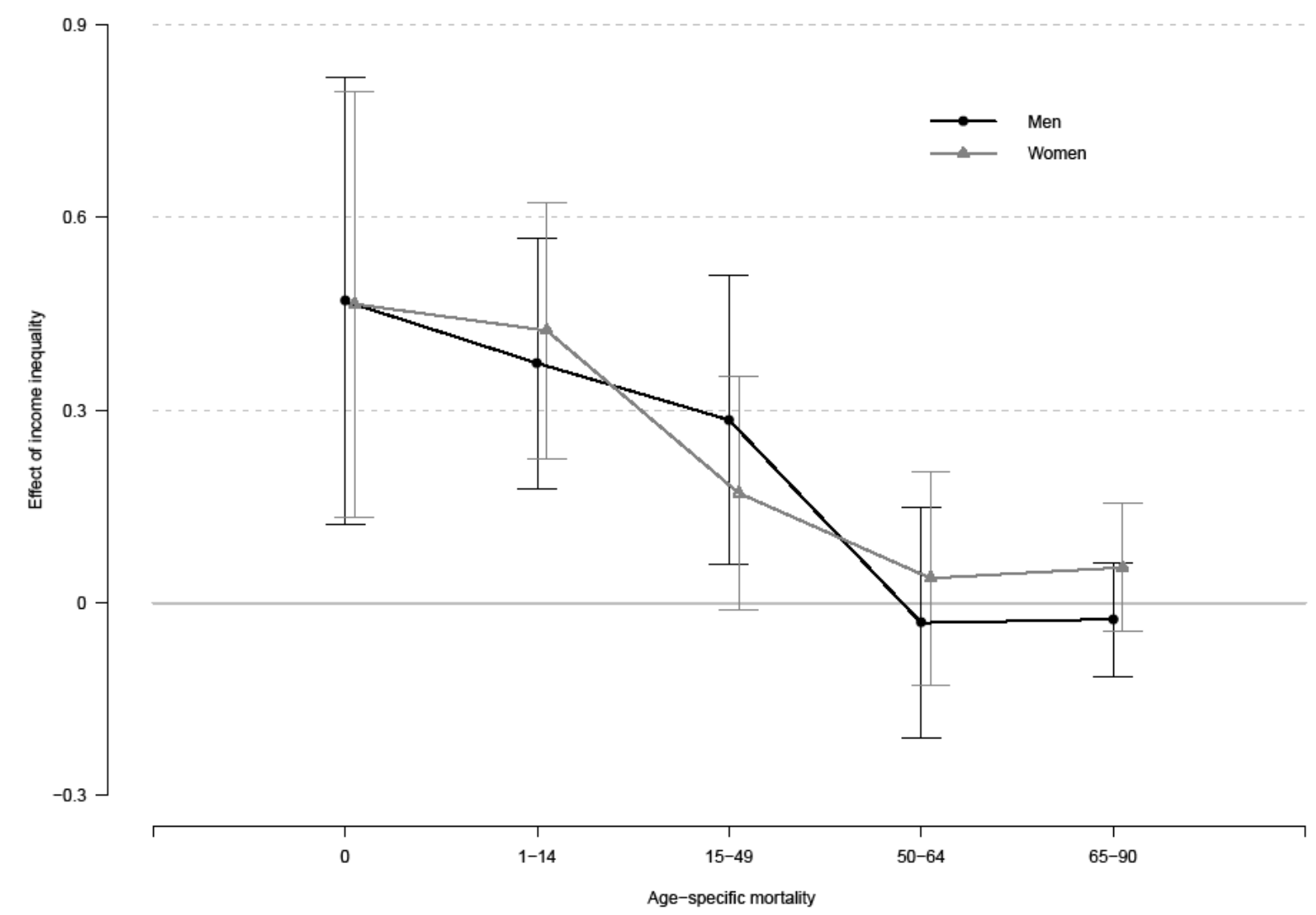

Regression coefficients for Gini index of income inequality on age-specific mortality rates.

Note: The coefficients are shown in Table 3. The models are estimated with all variables in $\log$ scale and control for GDP per capita, country random-effects and time fixed-effects and allow for autocorrelation in the residuals. 